\title{
Association between GABRG2 rs211037 polymorphism and idiopathic generalized epilepsies: a meta-analysis
}

\author{
Xiaohui Yang ${ }^{1}$, Hongyun Ding ${ }^{2}$, Hongyun $\mathrm{Wei}^{3}$, Jia Liư ${ }^{4}$, Pingping Liao ${ }^{4}$, Yuzhu Zhang ${ }^{4}$, Xiaomeng Wang ${ }^{4}$ and \\ Xiaosa $\mathrm{Chi}^{4^{*}}$
}

\begin{abstract}
Background: We performed this meta-analysis to investigate the association between GABRG2 rs211037polymorphism and the risk for idiopathic generalized epilepsies (IGEs).

Methods: Medline, Embase, Cochrane Library and Chinese National Knowledge Infrastructure (CNKI) databases were searched for eligible studies (until May 5, 2020) on the association between GABRG2 rs211037 polymorphism and IGE. The odds ratios were calculated using a fixed or random model in STATA 15.0 software. Subgroup analyses for ethnicity, age, source of controls, type of seizure syndrome and therapeutic responses were conducted.

Results: We found no significant associations between GABRG2 rs211037 polymorphism and the susceptibility to IGEs. In addition, no significant association was detected between GABRG2 rs211037 polymorphism and drug resistance in IGE patients. The results did not change after stratification by Asian population, healthy controls, children, juvenile myoclonic epilepsy, and childhood absence epilepsy.

Conclusion: The current studies indicated that the GABRG2 rs211037 polymorphism was not related to susceptibility or drug resistance of IGE. Further well-designed studies are needed to verify the results.
\end{abstract}

Keywords: GABRG2, rs211037, Idiopathic generalized epilepsies, Polymorphism

\section{Background}

Idiopathic generalized epilepsies (IGEs) are featured by recurring generalized seizures without intracranial lesions [1], affecting $0.3 \%$ of the general population and accounting for $30 \%$ of all epilepsy disorders [1]. Epilepsy with generalized tonic clonic seizures (EGTCS), childhood absence epilepsy (CAE), juvenile myoclonic epilepsy (JME) and juvenile absence epilepsy (JAE) and were common syndromes of IGEs [2]. The causes of IGE are highly heterogeneous and genetic factors seem to be an important one.

Previous studies indicated that disruption of the gamma-amino butyric acid (GABA)-mediated inhibitory

\footnotetext{
*Correspondence: Chi_xiaosa@163.com

${ }^{4}$ Department of Geriatrics, Affiliated Hospital of Qingdao University, 59 Haier Road, Qingdao, Shandong 266100, China

Full list of author information is available at the end of the article
}

neurotransmission results in neuronal hyperexcitability, which is proved to participate in epileptogenesis [3-5]. Genetic alterations can influence channel function, increase neuronal excitability and induce neuronal networks into synchronous activity, and lead to in epileptic seizures [6]. Recent studies have identified GABRG2 genetic variants in relation with increased risk of epilepsy, of which rs211037 (C588T) is receiving much attention [7]. The GABRG2 rs211037 variant may alter the transcription and translation efficiency of GABAA receptor subunits, modify the composition of receptor, and influence the sensitivity to extrinsic environmental signals [8].

The association between GABRG2 rs211037 polymorphism and the risk for IGE have been investigated in several studies. Nevertheless, the results are inconsistent. Haerian BS et.al. conducted a meta-analysis with 4

(c) The Author(s). 2021 Open Access This article is licensed under a Creative Commons Attribution 4.0 International License, which permits use, sharing, adaptation, distribution and reproduction in any medium or format, as long as you give appropriate credit to the original author(s) and the source, provide a link to the Creative Commons licence, and indicate if changes were made. The images or other third party material in this article are included in the article's Creative Commons licence, unless indicated otherwise in a credit line to the material. If material is not included in the article's Creative Commons licence and your intended use is not permitted by statutory regulation or exceeds the permitted use, you will need to obtain permission directly from the copyright holder. To view a copy of this licence, visit http://creativecommons.org/licenses/by/4.0/. 
studies included and found no significant association between GABRG2 rs211037 and the susceptibility to IGEs [7]. However, several studies investigating the association between GABRG2 rs211037 and IGEs since 2003. In the study, we performed an updated meta-analysis to assess the relationship between GABRG2 rs211037 and IGEs.

\section{Methods}

\section{Literature search strategy}

Eligible studies were searched in the databases of Medline, Embase, Wanfang, Cochrane Library and Chinese National Knowledge Infrastructure (CNKI) (until May 2020) using the following search keywords: 'epilepsy' OR 'seizure', 'polymorphism' OR 'variant' OR 'mutation', and 'GABARG2'. In addition, we searched the references of reviews and relevant studies. This meta-analysis was conducted according to Meta-analysis for Observational Studies in Epidemiology guidelines.
Inclusion and exclusion criteria

Two authors (Xiaohui Yang and Hongyun Wei) screened each eligible article independently, and a third author (Xiaosa Chi) would rejudge the article in case of any disagreement. The study inclusion criteria were: (1) assessing the relation between GABRG2 rs211037 polymorphism and IGEs; (2) case-control or cohort study; (3) providing sufficient data on genotype distributions; and (4) in English or Chinese language. Studies were excluded if they: (1) are reviews and meeting abstracts; (2) did not report sufficient data; and (3) are animal studies or in vitro experiments.

\section{Data extraction}

Baseline information were extracted in duplicates from all of the eligible studies by Xiaohui Yang and Hongyun Wei independently, and any dispute was figured out by discussion. The extracted data included: name of the

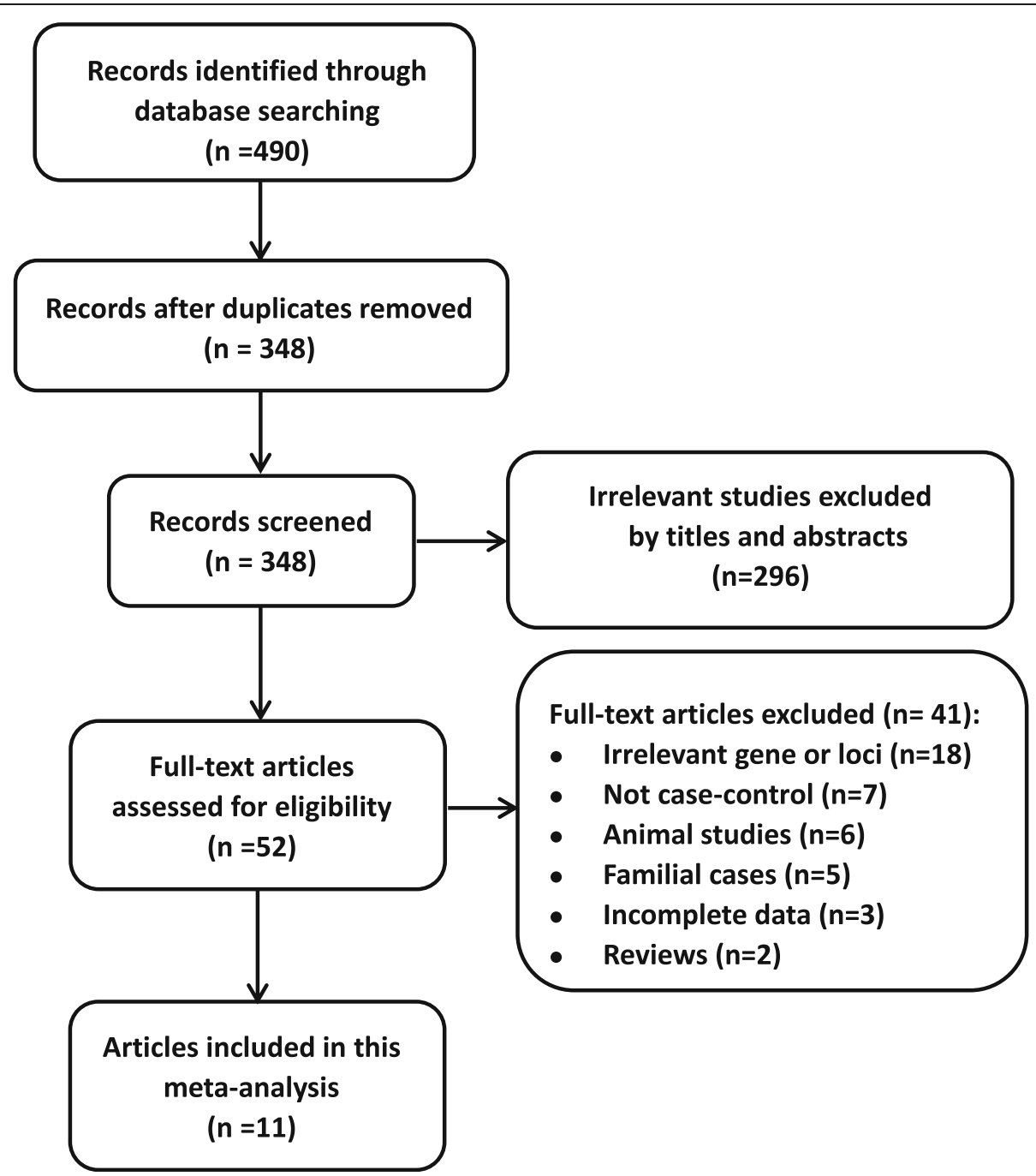

Fig. 1 Flow chart of study selection. Ultimately, 11 articles were identified 
Table 1 Baseline characteristic of eligible case-control studies

\begin{tabular}{|c|c|c|c|c|c|c|c|c|c|}
\hline Author & Year & Country & Ethnity & Type of epilepsy & Genotyping Methods & Control & Total & Case & Control \\
\hline Abou [9] & 2018 & Egypt & Asian & IGE & PCR-RFLP & healthy & 210 & 100 & 110 \\
\hline Balan [10] & 2013 & India & Asian & JME & AS-PCR & healthy & 500 & 235 & 265 \\
\hline Bhat [11] & 2018 & India & Asian & JME & PCR-RFLP & healthy & 150 & 50 & 100 \\
\hline Butila [12] & 2018 & Romania & Caucasians & IGE & PCR-RFLP & patients & 213 & 60 & 153 \\
\hline Chou [13] & 2007 & China & Asian & IGE & PCR-RFLP & healthy & 160 & 77 & 83 \\
\hline Gitai [14] & 2012 & Brazil & Mixed & JME & PCR-RFLP & healthy & 228 & 98 & 130 \\
\hline Haerian [15] & 2015 & Malaysia & Asian & IGE & MassARRAY & healthy & 1,254 & 176 & 1,078 \\
\hline Kananura [16] & 2002 & Germany & Caucasian & CAE & RT-PCR & healthy & 289 & 135 & 154 \\
\hline Kim [17] & 2012 & Korean & Asian & CAE & PCR & healthy & 242 & 35 & 207 \\
\hline Kinirons A [18] & 2006 & UK & NA & IGE & tSNP & healthy & 408 & 78 & 330 \\
\hline Kinirons B [18] & 2006 & Ireland & NA & IGE & tSNP & healthy & 400 & 117 & 283 \\
\hline Ponnala [19] & 2012 & India & Asian & IGE & PCR-RFLP & healthy or patients & 186 & 86 & 100 \\
\hline
\end{tabular}

$A S-P C R$ Allele-specific polymerase chain reaction, CAE childhood absence epilepsy, IGE childhood idiopathic generalized epilepsy, JME Juvenile myoclonic epilepsy, MasSARRAY matrixassisted laser desorption/ionization time of flight mass spectrometry, NA not available, $P C R$ - $R F L P$ polymerase chain reaction-restriction fragment length polymorphism, $R T-P C R$ reverse transcription- polymerase chain reaction, $t S N P$ a tagging single nucleotide polymorphism

first author, publication year, country of origin, ethnicity, source of cases and controls, study period, genotyping methods, quality control, the numbers of cases and controls, and frequencies of genotype.

\section{Statistical analysis}

We calculate the pooled odds ratios (ORs) and corresponding $95 \% \mathrm{CI}$ to estimate the strength of association between GABRG2 rs211037 polymorphism and the risk for IGE. The dominant model, recessive model, co-dominant model and allele model were conducted to evaluate the association. In addition, subgroup analyses were conducted for ethnicity, age, source of control (non-IGE or healthy control), JME, $\mathrm{CAE}$, and drug resistance. We calculated $\mathrm{Z}$ test to evaluate the significance of pooled ORs, and regarded $P<0.05$ as statistically significant.

We evaluated the inter-study heterogeneity by Cochran's Q test and $\mathrm{I}^{2}$ statistic. $\mathrm{I}^{2} \geq 50 \%$ was considered as statistically significant. In this condition, the randomeffects model was applied to count pooled OR; otherwise, the fixed-effects model was applied. Moreover, publication bias was evaluated using visual inspection of Funnel plot which was obtained from Begg's test. All data was analyzed with STATA (version 15.0; Stata Corp, College Station, TX).

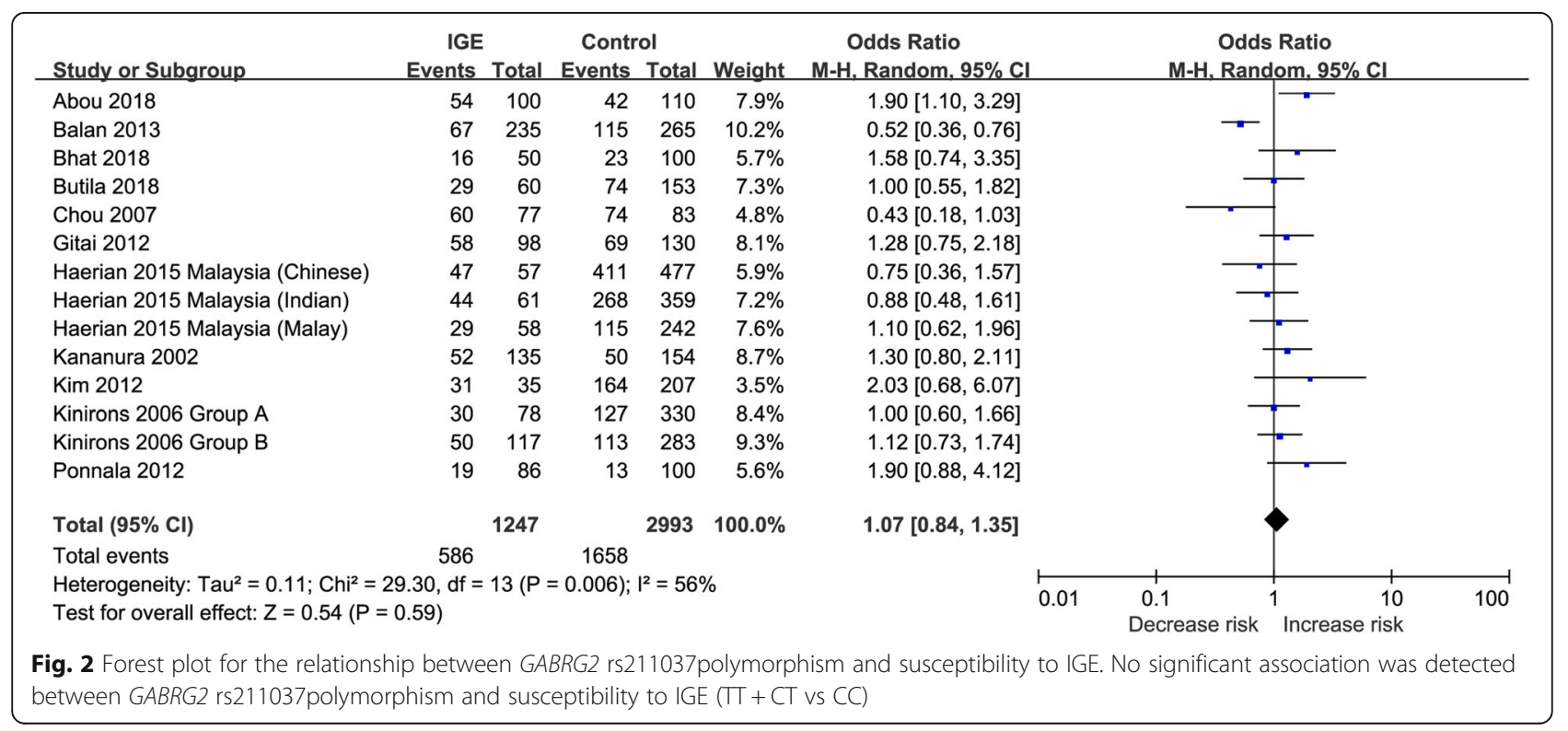


Table 2 Stratified analysis of GABRG2 rs211037 polymorphism on IGE

\begin{tabular}{|c|c|c|c|c|c|c|c|c|c|c|}
\hline \multirow[t]{2}{*}{ Variables } & \multicolumn{2}{|l|}{$\mathrm{TT}+\mathrm{CT}$ vs $\mathrm{CC}$} & \multicolumn{2}{|l|}{$\mathrm{TT}$ vs $\mathrm{CT}+\mathrm{CC}$} & \multicolumn{2}{|l|}{ TT vs CC } & \multicolumn{2}{|l|}{ CT vs CC } & \multicolumn{2}{|l|}{ T vs $C$} \\
\hline & OR $(95 \% \mathrm{Cl})$ & $P_{\text {het }}$ & OR $(95 \% \mathrm{Cl})$ & $P_{\text {het }}$ & OR $(95 \% \mathrm{Cl})$ & $P_{\text {het }}$ & OR $(95 \% \mathrm{Cl})$ & $P_{\text {het }}$ & OR $(95 \% \mathrm{Cl})$ & $P_{\text {het }}$ \\
\hline Total & $1.07[0.84,1.35]$ & 0.006 & $1.04[0.72,1.49]$ & 0.007 & $1.10[0.73,1.67]$ & 0.005 & $0.99[0.84,1.16]$ & 0.070 & $1.06[0.87,1.31]$ & $<0.001$ \\
\hline \multicolumn{11}{|l|}{ Ethnicity } \\
\hline Asian & $1.04[0.70,1.55]$ & $<0.001$ & $1.10[0.69,1.74]$ & 0.005 & $1.15[0.65,2.02]$ & 0.003 & $0.95[0.67,1.36]$ & 0.030 & $1.06[0.77,1.47]$ & $<0.001$ \\
\hline Healthy control & $1.15[0.97,1.38]$ & 0.250 & $1.11[0.73,1.68]$ & 0.003 & $1.16[0.72,1.87]$ & 0.004 & $1.12[0.93,1.36]$ & 0.240 & $1.10[0.89,1.35]$ & 0.003 \\
\hline JME & $0.97[0.47,2.02]$ & 0.004 & $1.36[0.86,2.15]$ & 0.190 & $1.30[0.61,2.75]$ & 0.080 & $0.72[0.36,1.44]$ & 0.060 & $1.08[0.57,2.04]$ & $<0.001$ \\
\hline CAE & $1.42[0.92,2.20]$ & 0.470 & $1.05[0.57,1.94]$ & 0.400 & $1.30[0.59,2.86]$ & 0.520 & $1.49[0.94,2.37]$ & 0.590 & $1.23[0.89,1.69]$ & 0.630 \\
\hline Children & $1.19[0.76,1.88]$ & 0.050 & $0.98[0.44,2.20]$ & 0.006 & $1.14[0.40,3.27]$ & 0.002 & $1.28[0.96,1.72]$ & 0.460 & $1.07[0.68,1.69]$ & $<0.001$ \\
\hline Drug resistance & $1.64[0.87,3.07]$ & 0.002 & $1.97[0.57,6.79]$ & 0.020 & $2.84[0.61,13.25]$ & 0.002 & $1.41[0.84,2.37]$ & 0.040 & $1.70[0.93,3.11]$ & $<0.001$ \\
\hline
\end{tabular}

CAE childhood absence epilepsy, JME Juvenile myoclonic epilepsy; $P_{\text {het }} P$ value of Q-test for heterogeneity

\section{Results}

\section{Study selection}

Altogether, 490 records were yielded by the initial search, leaving 348 after duplicate removal. After manual screening by titles and abstracts, 52 papers were selected (Fig. 1). Fifty two full-text studies were used for further evaluation, and eventually, 11 articles were included [919]. Finally, 1,161 IGE patients and 2,993 controls were included in the meta-analysis. The detailed information of included studies is presented in Table 1.

\section{GABRG2 rs211037polymorphism and susceptibility to IGE}

No significant association was detected between GABRG2 rs211037 polymorphism and the risk of IGE $(\mathrm{TT}+\mathrm{CT}$ vs $\mathrm{CC}: \quad \mathrm{OR}=1.07,95 \% \mathrm{CI}=0.84-1.35, \quad P=$ 0.006, Fig. 2). Further subgroup analysis also showed no significant associations after considering factors of source of control (inclusion of healthy controls in the control group $)(\mathrm{TT}+\mathrm{CT}$ vs $\mathrm{CC}: \mathrm{OR}=1.15,95 \% \mathrm{CI}=$ $0.97-1.38, P=0.250$, Table 2 ), ethnicity (Asian patients) $(\mathrm{TT}+\mathrm{CT}$ vs $\mathrm{CC}: \mathrm{OR}=1.04, \quad 95 \% \mathrm{CI}=0.70-1.55, \quad P<$ 0.001 , Fig. 3), and age (children with IGE) (TT + CT vs CC: $\mathrm{OR}=1.19,95 \% \mathrm{CI}=0.76-1.88, P=0.050$, Table 2 ).
When stratified by seizure syndrome, we found no significant relationship in patients with CAE. Besides, the GABRG2 rs211037 polymorphism was not significantly related to the risk of JME.

We further performed a subgroup meta-analysis to explore the relationship between GABRG2 rs211037 polymorphism and drug resistance in patients with IGE, and no significant association was detected (TT $+\mathrm{CT}$ vs CC: $\mathrm{OR}=1.64,95 \% \mathrm{CI}=0.87-3.07, P=0.002$, Fig. 4).

\section{Publication bias}

The symmetrical Begg's funnel plot suggested no publication bias (Fig. 5). No publication bias was detected by Egger's test $(t=1.50, P=0.159)$.

\section{Discussion}

Previous studies concerning the role of GABRG2 in IGEs have come to controversial results, so in this study, we performed the meta-analysis to investigate the association of GABRG2 rs211037 polymorphism with the risk for IGE. The results showed no relationship between GABRG2 rs211037 polymorphism and IGE. Also no significant associations were found in subgroups of healthy

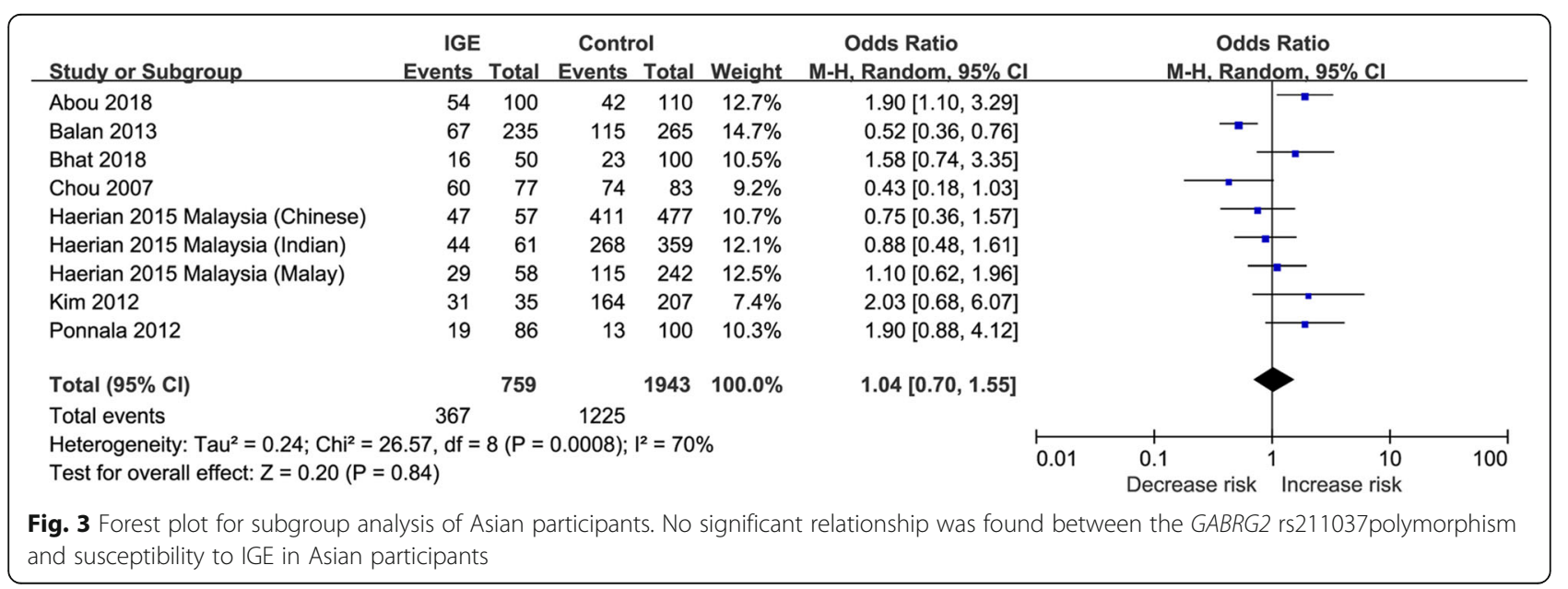




\begin{tabular}{|c|c|c|c|c|c|c|c|c|c|}
\hline Study or Subgroup & $\begin{array}{c}\text { IGE } \\
\text { Events }\end{array}$ & Total & $\begin{array}{l}\text { Contr } \\
\text { Events }\end{array}$ & Total & Weight & $\begin{array}{c}\text { Odds Ratio } \\
\mathrm{M}-\mathrm{H}, \text { Random, } 95 \% \mathrm{Cl}\end{array}$ & \multicolumn{3}{|c|}{$\begin{array}{c}\text { Odds Ratio } \\
\text { M-H, Random, } 95 \% \mathrm{Cl}\end{array}$} \\
\hline Abou 2018 & 38 & 54 & 16 & 46 & $19.8 \%$ & $4.45[1.92,10.34]$ & & - & \\
\hline Balan 2013 & 75 & 240 & 56 & 198 & $27.0 \%$ & $1.15[0.76,1.74]$ & & & \\
\hline Butila 2018 & 10 & 11 & 19 & 49 & $6.8 \%$ & $15.79[1.87,133.46]$ & & & \\
\hline Kumari 2010 & 56 & 122 & 122 & 259 & $26.7 \%$ & $0.95[0.62,1.47]$ & & & \\
\hline Ponnala 2012 & 12 & 56 & 16 & 70 & $19.7 \%$ & $0.92[0.39,2.15]$ & & & \\
\hline Total $(95 \% \mathrm{Cl})$ & & 483 & & 622 & $100.0 \%$ & $1.64[0.87,3.07]$ & & & \\
\hline Total events & 191 & & 229 & & & & & & \\
\hline $\begin{array}{l}\text { Heterogeneity: } \mathrm{Tau}^{2}= \\
\text { Test for overall effect }\end{array}$ & $\begin{array}{l}.34 ; \mathrm{Chi}^{2} \\
=1.53(\mathrm{P}\end{array}$ & $\begin{array}{l}=16.43 \\
=0.13\end{array}$ & $\mathrm{df}=4($ & $=0.0$ & $002) ; 1^{2}=7$ & 0.01 & $\begin{array}{c}0.1 \\
\text { Decrease risk }\end{array}$ & $\begin{array}{r}10 \\
\text { Increase risk }\end{array}$ & 100 \\
\hline
\end{tabular}

control, Asian ethnicity, JME, CAE or children. Furthermore, the GABRG2 rs211037 polymorphism was not significantly related to drug resistance.

As a major inhibitory neurotransmitter, GABA affects neuronal excitability and network interactions in the brain [20]. Its binding to receptors leads to the influx of chloride ions through ion channels, resulting in fast postsynaptic inhibition in the brain [21]. Expression and conformation modification of GABAA receptors may be involved in epileptogenesis, such as mRNA lability, irregular subunit folding, distortions of the GABA channel, and glycosylation defects [22, 23]. Mutations in GABRG2 affect the expression and trafficking of GABAA receptors to the cell membrane $[4,24]$, and are reported to be associated with IGEs [25]. In addition, the $\gamma 2$ subunit has been proved to influence the kinetics, synaptic and postsynaptic clustering and maintenance of GABAA-associated channels [26-28]. All these may contribute to epilepsy development. Moreover, lower amplitude of GABA-activated currents was detected in HEK293 cells which expresses the mutant GABAA receptor, suggesting that dysfunction of this receptor may lead to seizures [29]. Further studies are needed to explore the effect of GABAA in idiopathic epilepsy. In addition, we performed a subgroup analysis in Asian people, but failed to detect any association, which is inconsistent with previous studies showing that GABRG2 rs211037 polymorphism is associated with susceptibility to IGE in Asian people. More studies are needed to clarify this discrepancy. In addition, there are relevant few studies performed in Caucasian populations. Therefore, future studies should be performed with more ethnicities.

Moreover, no association was detected when stratified by subtype of epilepsy syndrome including CAE and JME. Seizure syndromes in IGE have common genetic

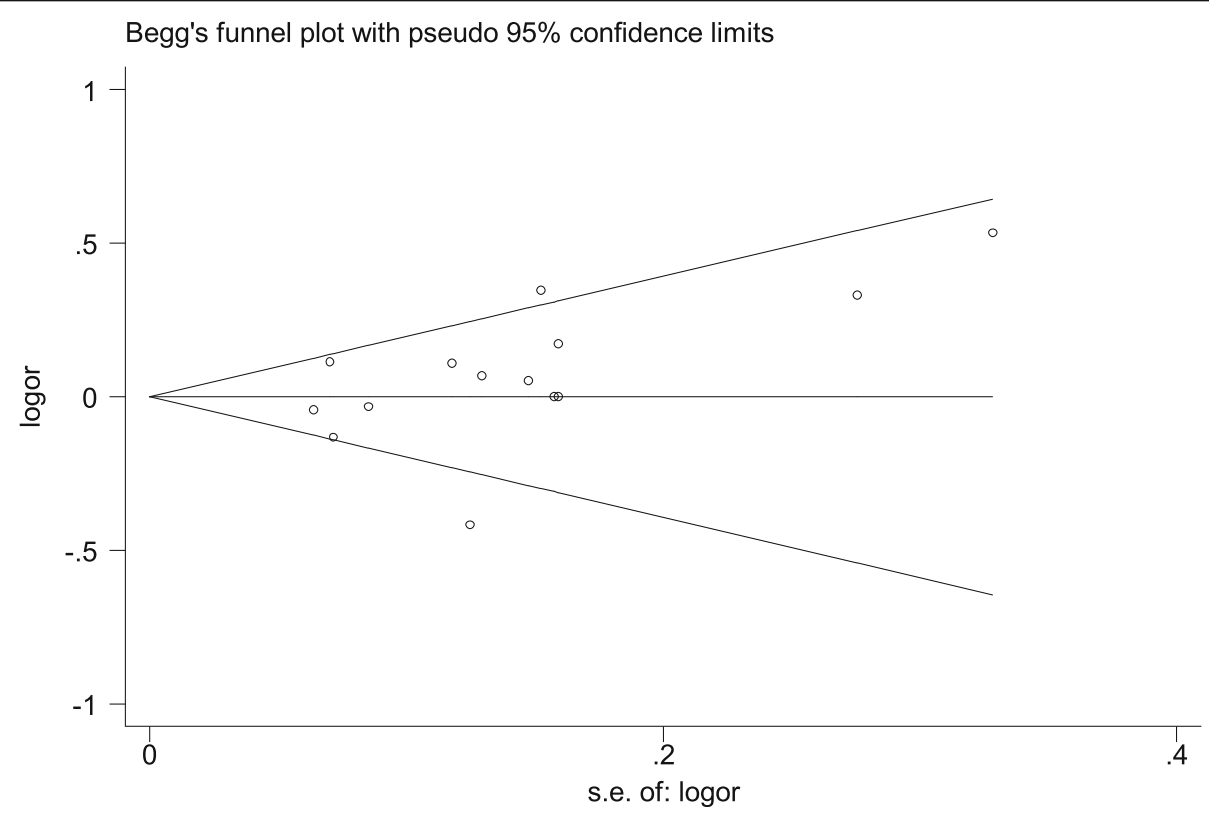

Fig. 5 Begg's funnel plot. The funnel plot suggested no publication bias among the eligible studies 
predisposition but various clinical manifestations. The age at onset of the various subgroups included in IGEs differed. The reasons for the discrepancy between previous studies and ours in the associations of GABRG2 rs211037 polymorphism with IGE may be the lack of specific subtype analysis in previous studies. Meanwhile, a great many genes participated in the mechanisms of IGEs, and the effect of GABRG2 on IGEs may be little [13]. Therefore, genome-wide association studies are essential to explore the association between GABRG2 and IGEs.

In this meta-analysis, we also found no relation between GABRG2 rs211037 polymorphism and drug resistance. It has been reported that the expression of GABAA receptor subunit in drug-resistant rats differs from that in the drug-responsive rats of temporal lobe epilepsy [30]. Abou et al. showed that the GABRG2 rs211037 polymorphism may contribute to the resistance to antiepileptic drugs (AEDs) among Egyptian children [9]. Several AEDs such as topiramate, gabapentin, and phenobarbital target the GABAA receptor and alter the concentrations of GABA [31]. Nevertheless, relevant studies are still limited, and further research is needed to clarify the relationship and the underlying pathogenesis, which may contribute to identifying therapeutic targets for the development of novel AEDs.

Our study has some limitations. First, our searches were made in limited databases, thus other relevant paper might be missed out. Second, relatively few cases and controls were available in some subgroups, which may influence the power of the test. Third, in most studies Asian participants were employed, so our results may not be suitable for other ethnicities. Finally, further analysis of gene-gene and loci-loci interactions was not conducted on account of insufficient data.

In conclusion, we found no associations between the GABRG2 rs211037 polymorphism and the risk for IGE. Subgroup analysis stratified by ethnicity, age, healthy control and drug resistance provided similar results. Further well-designed case-control studies with larger sample sizes are needed.

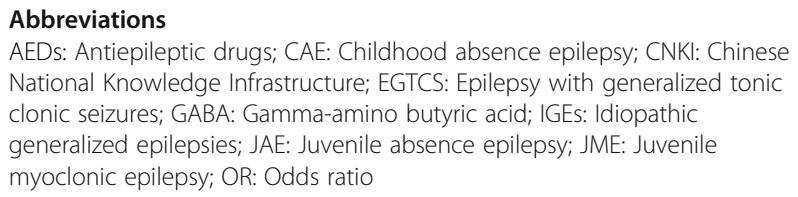

Abbreviations

AEDs: Antiepileptic drugs; CAE: Childhood absence epilepsy; CNKI: Chinese National Knowledge Infrastructure; EGTCS: Epilepsy with generalized tonic clonic seizures; GABA: Gamma-amino butyric acid; IGEs: Idiopathic generalized epilepsies; JAE: Juvenile absence epilepsy; JME: Juvenile myoclonic epilepsy; OR: Odds ratio

\section{Acknowledgements}

Not applicable.

\section{Authors' contributions}

XSC designed the study, interpreted the data and revised the study. HYD and $\mathrm{XHY}$ conducted the systematic search and extracted the eligible studies. $X H Y$ and HYW extracted and analyzed the data. HYD and JL analyzed the data. PPL, YZZ and XMW interpreted the data. XHY drafted the study. All the authors read and approved the final manuscript.

\section{Funding}

This study was supported by the National Natural Science Foundation of Shandong, China (item number ZR2019PH040) and the National Natural Science Foundation of China (item number 81901321).

Availability of data and materials

The data in this study are available on reasonable request.

\section{Declarations}

Ethics approval and consent to participate

Not applicable.

Consent for publication

All authors consented to publish this study.

\section{Competing interests}

The authors declare no conflicts of interest.

\section{Author details}

'Department of Respiratory, Affiliated Hospital of Qingdao University, Qingdao 266000, China. ${ }^{2}$ Department of Gastroenterology, Qingdao Municipal Hospital Group, Qingdao 266000, China. ${ }^{3}$ Department of Gastroenterology, Affiliated Hospital of Qingdao University, Qingdao 266000, China. ${ }^{4}$ Department of Geriatrics, Affiliated Hospital of Qingdao University, 59 Haier Road, Qingdao, Shandong 266100, China.

Received: 28 September 2020 Accepted: 15 April 2021

Published online: 24 May 2021

\section{References}

1. Auten JD, Kuhne MA, Walker HM 2nd, Porter HO. Neurologic decompression sickness following cabin pressure fluctuations at high altitude. Aviat Space Environ Med. 2010;81(4):427-30. https://doi.org/10.33 57/ASEM.2406.2010

2. Engel J. A proposed diagnostic scheme for people with epileptic seizures and with epilepsy: report of the ILAE task force on classification and terminology. Epilepsia. 2001;42(6):796-803. https://doi.org/10.1046/j.1528-11 57.2001.10401.x.

3. Olsen RW, Avoli M. GABA and epileptogenesis. Epilepsia. 1997;38(4):399-407. https://doi.org/10.1111/j.1528-1157.1997.tb01728.x.

4. Macdonald RL, Gallagher MJ, Feng H-J, Kang J. GABAA receptor epilepsy mutations. Biochem Pharmacol. 2004;68(8):1497-506. https://doi.org/10.101 6/j.bcp.2004.07.029.

5. Noebels JL. The biology of epilepsy genes. Annu Rev Neurosci. 2003;26(1): 599-625. https://doi.org/10.1146/annurev.neuro.26.010302.081210.

6. Hedrich U, Maljevic S, Lerche $H$. Mechanisms of genetic epilepsies. Neuroforum. 2013;4(2):23-30

7. Haerian BS, Baum L. GABRG2 rs211037 polymorphism and epilepsy: a systematic review and meta-analysis. Seizure. 2013;22(1):53-8. https://doi. org/10.1016/j.seizure.2012.10.007

8. Wang DD, Kriegstein AR. Defining the role of GABA in cortical development J Physiol. 2009;587(9):1873-9. https://doi.org/10.1113/jphysiol.2008.167635.

9. El A, Ella SS, Tawfik MA, El A, Fotoh WMM, Soliman OAM. The genetic variant "C588T" of GABARG2 is linked to childhood idiopathic generalized epilepsy and resistance to antiepileptic drugs. Seizure. 2018;60:39-43.

10. Balan S, Sathyan S, Radha SK, Joseph V, Radhakrishnan K, Banerjee M. GABRG2, rs211037 is associated with epilepsy susceptibility, but not with antiepileptic drug resistance and febrile seizures. Pharmacogenet Genomics. 2013;23(11):605-10. https://doi.org/10.1097/FPC.0000000000000000.

11. Bhat M, Guru SA, Mir R, Waza AA, Zuberi M, Sumi MP, et al. Association of GABAA receptor gene with epilepsy syndromes. J Mol Neurosci. 2018;65(2): 141-53. https://doi.org/10.1007/s12031-018-1081-7.

12. Butila AT, Zazgyva A, Sin Al, Szabo ER, Tilinca MC. GABRG2 C588T gene polymorphisms might be a predictive genetic marker of febrile seizures and generalized recurrent seizures: a case-control study in a Romanian pediatric population. Arch Med Sci. 2018;14(1):157-66.

13. Chou IC, Lee CC, Tsai CH, Tsai Y, Wan L, Hsu YA, et al. Association of GABRG2 polymorphisms with idiopathic generalized epilepsy. Pediatr Neurol. 2007;36(1):40-4. https://doi.org/10.1016/j.pediatrneurol.2006.09.011. 
14. Gitai LL, de Almeida DH, Born JP, Gameleira FT, de Andrade TG, Machado LC, et al. Lack of association between rs211037 of the GABRG2 gene and juvenile myoclonic epilepsy in Brazilian population. Neurol India. 2012;60(6): 585-8. https://doi.org/10.4103/0028-3886.105191.

15. Haerian BS, Baum L, Kwan P, Cherny SS, Shin JG, Kim SE, et al. Contribution of GABRG2 polymorphisms to risk of epilepsy and febrile seizure: a multicenter cohort study and meta-analysis. Mol Neurobiol. 2016;53(8): 5457-67. https://doi.org/10.1007/s12035-015-9457-y.

16. Kananura C, Haug K, Sander T, Runge U, Gu W, Hallmann K, et al. A splicesite mutation in GABRG2 associated with childhood absence epilepsy and febrile convulsions. Arch Neurol. 2002;59(7):1137-41. https://doi.org/10.1 001/archneur.59.7.1137.

17. Kim YO, Kim MK, Nam TS, Jang SY, Park KW, Kim EY, et al. Mutation screening of the gamma-aminobutyric acid type-A receptor subunit gamma2 gene in Korean patients with childhood absence epilepsy. J Clin Neurol. 2012;8(4):271-5. https://doi.org/10.3988/jcn.2012.8.4.271.

18. Kinirons P, Cavalleri GL, Shahwan A, Wood NW, Goldstein DB, Sisodiya SM, et al. Examining the role of common genetic variation in the gamma2 subunit of the GABA(A) receptor in epilepsy using tagging SNPs. Epilepsy Res. 2006;70(2-3):229-38. https://doi.org/10.1016/j.eplepsyres.2006.05.009.

19. Ponnala S, Chaudhari JR, Jaleel MA, Bhiladvala D, Kaipa PR, Das UN, et al. Role of MDR1 C3435T and GABRG2 C588T gene polymorphisms in seizure occurrence and MDR1 effect on anti-epileptic drug (phenytoin) absorption. Genet Test Mol Biomarkers. 2012;16(6):550-7. https://doi.org/10.1089/gtmb.2 011.0225 .

20. Wang $X, X u M, D u L$. Association analysis of $Y 2$ subunit of $y$-aminobutyric acid (GABA) type A receptor and voltage-gated sodium channel type II apolypeptide gene mutation in southern Chinese children with febrile seizures. J Child Neurol. 2007;22(6):714-9. https://doi.org/10.1177/0883073 807304002.

21. Macdonald RL, Olsen RW. GABAA receptor channels. Annu Rev Neurosci. 1994;17(1):569-602. https://doi.org/10.1146/annurev.ne.17.030194.003033.

22. Reid CA, Berkovic SF, Petrou S. Mechanisms of human inherited epilepsies, Prog Neurobiol. 2009;87(1):41-57. https://doi.org/10.1016/j.pneurobio.2008. 09.016.

23. Macdonald RL, Kang JQ, Gallagher MJ. Mutations in GABAA receptor subunits associated with genetic epilepsies. J Physiol. 2010;588(11):1861-9. https://doi.org/10.1113/jphysiol.2010.186999.

24. Hirose S. A new paradigm of channelopathy in epilepsy syndromes: intracellular trafficking abnormality of channel molecules. Epilepsy Res. 2006; 70:206-17. https://doi.org/10.1016/j.eplepsyres.2005.12.007.

25. Cossette P, Lachance-Touchette P, Rouleau GA. Mutated GABAA receptor subunits in idiopathic generalized epilepsy. Jasper's Basic Mechanisms of the Epilepsies. 4th ed; 2012.

26. Günther U, Benson J, Benke D, Fritschy J-M, Reyes G, Knoflach F, et al. Benzodiazepine-insensitive mice generated by targeted disruption of the gamma 2 subunit gene of gamma-aminobutyric acid type A receptors. Proc Natl Acad Sci U S A. 1995;92(17):7749-53. https:/doi.org/10.1073/pnas.92.17.7749.

27. Essrich C, Lorez M, Benson JA, Fritschy J-M, Lüscher B. Postsynaptic clustering of major GABA A receptor subtypes requires the $\gamma 2$ subunit and gephyrin. Nat Neurosci. 1998; 1(7):563-71. https://doi.org/10.1038/2798.

28. Schweizer C, Balsiger S, Bluethmann H, Mansuy IM, Fritschy J-M, Mohler H, et al. The $\gamma 2$ subunit of GABAA receptors is required for maintenance of receptors at mature synapses. Mol Cell Neurosci. 2003;24(2):442-50. https:// doi.org/10.1016/S1044-7431(03)00202-1.

29. Cossette P, Liu L, Brisebois K, Dong H, Lortie A, Vanasse M, et al. Mutation of GABRA1 in an autosomal dominant form of juvenile myoclonic epilepsy. Nat Genet. 2002;31 (2):184-9. https://doi.org/10.1038/ng885.

30. Bethmann K, Fritschy J-M, Brandt C, Löscher W. Antiepileptic drug resistant rats differ from drug responsive rats in GABAA receptor subunit expression in a model of temporal lobe epilepsy. Neurobiol Dis. 2008;31(2):169-87. https://doi.org/10.1016/j.nbd.2008.01.005.

31. Salam SMA, Rahman HM, Karam RA. GABRG2 gene polymorphisms in Egyptian children with simple febrile seizures. Indian J Pediatr. 2012;79(11): 1514-6. https://doi.org/10.1007/s12098-011-0564-0.

\section{Ready to submit your research? Choose BMC and benefit from:}

- fast, convenient online submission

- thorough peer review by experienced researchers in your field

- rapid publication on acceptance

- support for research data, including large and complex data types

- gold Open Access which fosters wider collaboration and increased citations

- maximum visibility for your research: over $100 \mathrm{M}$ website views per year

At BMC, research is always in progress.

Learn more biomedcentral.com/submissions 